\title{
Analysis of thermoelectric geometry in a concentrated photovoltaic- thermoelectric under varying weather conditions
}

(i) The corrections made in this section will be reviewed and approved by a journal production editor.

Samson Shittu Writing - review \& editing Writing - original draft Validation Software Conceptualization ${ }^{\text {a }}$, Guiqiang Li Project administration Supervision ${ }^{\mathrm{a}, \mathrm{Q}}$ Guiqiang.Li@hull.ac.uk, Xin Tang Formal analysis ${ }^{\text {b }}$, Xudong Zhao Funding acquisition a, ${ }^{\mathrm{a}}$ Xudong.Zhao@hull.ac.uk, Xiaoli Ma Supervision a , Ali Badiei Visualization $^{\text {a }}$

${ }^{a}$ Centre for Sustainable Energy Technologies, University of Hull, HU6 7RX, UK

'bchool of Energy and Power Engineering, Xi'an Jiaotong University, Xi'an, 710049, China

${ }^{\square}$ Corresponding author.

${ }^{\mathrm{Q}}$ Corresponding author.

\begin{abstract}
This study presents a detailed three-dimensional numerical investigation of the optimum thermoelectric geometry in a hybrid concentrated photovoltaicthermoelectric system under varying weather conditions. Four different thermoelectric leg geometries are considered and their effects on the performance of the hybrid system are studied. The effects of thermoelectric leg height, cross-sectional area and ceramic height on the hybrid system performance are investigated. Furthermore, the effect of convective heat transfer coefficient on the hybrid system performance is studied. The performance of the hybrid system with optimized thermoelectric geometry is compared with that of the hybrid system with original geometry for summer climatic conditions in London, United Kingdom for a duration of $24 \mathrm{~h}$. Results show that thermoelectric geometry optimization can reduce significantly, the negative impacts of the variable weather conditions on the hybrid system performance. Furthermore, results show that the maximum hybrid system power output density with the optimized thermoelectric geometry decreased by $48.29 \%$ when the original geometry is used. This study will provide useful insights into thermoelectric geometry optimization in a hybrid system and optimum thermoelectric geometry for performance enhancement.
\end{abstract}

Keywords: Photovoltaic-thermoelectric; Geometry optimization; Transient study; Thermal management; Finite element method

\section{Introduction}

The use of fossil fuel negatively affects the climate and health of people due to air pollution [1]. Therefore, renewable energy sources like solar energy is considered as an ideal alternative energy source because it offers unique advantages such as being inexhaustible, free, reliable and clean energy source [2]. Solar energy can be utilized commonly by converting it into electricity and heat [3]. Electricity can be generated directly by the photovoltaic (PV) from solar energy conversion therefore, the PV is one of the most attractive clean electricity generation technologies $[4,5]$.

A thermoelectric generator (TEG) converts waste heat to electricity directly via the Seebeck effect [6]. Since the photovoltaic mainly utilizes the solar spectrum's visible and ultra-violet parts and the infrared part is used by the thermoelectric [7], combining both the photovoltaic and thermoelectric will enable a more efficient energy harvesting from the solar spectrum [8]. Spectrum splitting method or direct coupling method can be used to design hybrid photovoltaic-thermoelectric systems [9]. Spectrum splitting involves the use of beam splitters to separate the solar radiation at a specific cut-off wavelength for energy conversion use by the photovoltaic and the thermoelectric generator [10] while direct coupling does not involve the use of any splitter as the TEG is placed directly behind the PV in a parallel form [11 ].

Geometry optimization has been found to be an effective method for performance enhancement of thermoelectric generators in stand-alone and hybrid systems [12, 13]. Fan et al. [14] found the optimal thermoelectric leg cross-sectional area and length for obtaining maximum TEG power output using a comprehensive mathematical model. Results revealed that the maximum power output density decreases as leg length increase. Similarly, Cheng et al. [15] performed an experiment study on thermoelectric leg area and length effects on module performance. They found that optimizing the leg length and area enabled the achievement of maximum power output. He et al. [16] optimized the thermoelectric geometry in a TEG and results showed that long thermoelectric legs cause an increase in electrical potential and internal resistance.

Thermoelectric geometry in a photovoltaic-thermoelectric system was optimized by Li et al. [17] under steady state conditions and they found the optimal TE geometry in a PV-TE and TE only system to be different. Hashim et al. [18] found the optimal thermoelectric geometry for maximum PV-TE power output using a comprehensive model. The authors argued that quantity of thermoelectric material consumed must be consider when optimizing geometry for maximum output power. Furthermore, Mahmoudinezhad et al. [19] argued in favor of thermoelectric geometry optimization in a hybrid system to obtain increased power output. Lamba et al. [20] found that thermoelectric leg length has an inverse relationship with temperature difference in a CPV-TE system. In addition, Kossyvakis et al. [21] found that short thermoelectric legs provide enhanced performance in a hybrid photovoltaic-thermoelectric system. Motiei et al. [22] study the photovoltaic- 
thermoelectric system performance under transient conditions with a two-dimensional model. A duration of $24 \mathrm{~h}$ was considered for the study and they found that the TEG enhanced the PV power output and efficiency by $5.06 \%$ and $0.59 \%$, respectively.

Fallah Kohan et al. [23] used finite volume method to study a hybrid photovoltaic-thermoelectric system. Result revealed that the photovoltaic-thermoelectric system could provide a higher power output under specific environmental conditions, in comparison to the photovoltaic only system. Furthermore, the performance of a thermally coupled concentrated photovoltaic-thermoelectric system was investigated by Zhu et al. [24] using a three-dimensional model. They found that the additional electrical energy generated by the TEG in the CPV-TE enabled the hybrid system to achieve a peak efficiency of about $23 \%$ compared to that of the PV only (19\%). Recently, Abdo et al. [25] introduced a new design for a photovoltaic-thermoelectric system with microchannel heat sink placed in the middle of the photovoltaic and the thermoelectric generator. Results showed that the new system could operate safely at higher concentration ratios in comparison to conventional system and a better performance could be obtained.

Based on the literature review above, it is obvious that the hybrid photovoltaic-thermoelectric system is feasible and can provide enhanced performance compared to the photovoltaic only system. Furthermore, it has been clearly shown that thermoelectric geometry optimization in a stand-alone and hybrid photovoltaicthermoelectric system can cause significant enhancement of system performance. In addition, the advantages of performing transient study over steady-state study has been shown and the significance of three-dimensional studies has been demonstrated. However, there are currently very few studies on thermoelectric geometry optimization in a hybrid photovoltaic-thermoelectric under transient conditions. Furthermore, the effects of thermoelectric leg geometry, height, cross-sectional area and ceramic height have not been studied in a hybrid photovoltaic-thermoelectric system.

Therefore, a detailed three-dimensional numerical investigation on optimum thermoelectric geometry in a concentrated photovoltaic-thermoelectric (CPV-TE) system under varying weather conditions is presented in this study. Furthermore, the effects of the thermoelectric leg geometry, height, cross-sectional area and ceramic height on the concentrated photovoltaic-thermoelectric system performance are studied and optimum values for these parameters are found. A performance comparison of the CPV-TE with and without thermoelectric geometry optimization is made for summer climatic conditions in London, United Kingdom. Four different cases are considered corresponding to different thermoelectric leg geometries and their effects on the CPV-TE performance are analyzed. Furthermore, the effect of convective heat transfer coefficient on the CPV-TE performance is studied.

The remaining part of this paper is organized as follows: Section 2 presents a detailed description of the different thermoelectric geometries considered and materials used in this study. Section 3 presents the numerical model for the photovoltaic, thermoelectric generator and hybrid system while Section 4 presents the results obtained and corresponding discussion. Finally, Section 5 presents the main conclusions from this study.

\section{Geometry and material description}

The four different thermoelectric leg geometries which are considered in this study are shown in Fig. 1. All layers of the photovoltaic are in direct contact and of equal area. A commercial bismuth telluride $\left(\mathrm{Bi}_{2} \mathrm{Te}_{3}\right)$ thermoelectric generator $(40 \mathrm{~mm} \times 40 \mathrm{~mm})$ manufactured by Thermonamic Co. (TEP1-1264-3.4) is used in this study. The TEG is made up of $126 \mathrm{n}$-type and p-type thermoelectric leg pairs which are connected in series electrically and thermally in parallel. Furthermore, air cooling is used in this study and the heat sink is made of copper material. Geometric parameters of the hybrid system used for this numerical investigation are shown in Table 1 and Table 2 shows the cubic polynomial functions which describe the thermoelectric material properties used which are dependent on temperature. 
resiex

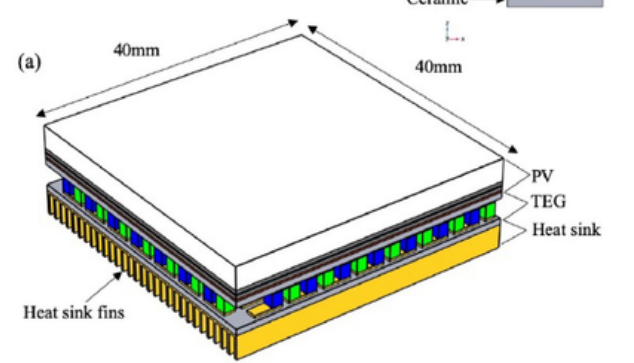

Case 1

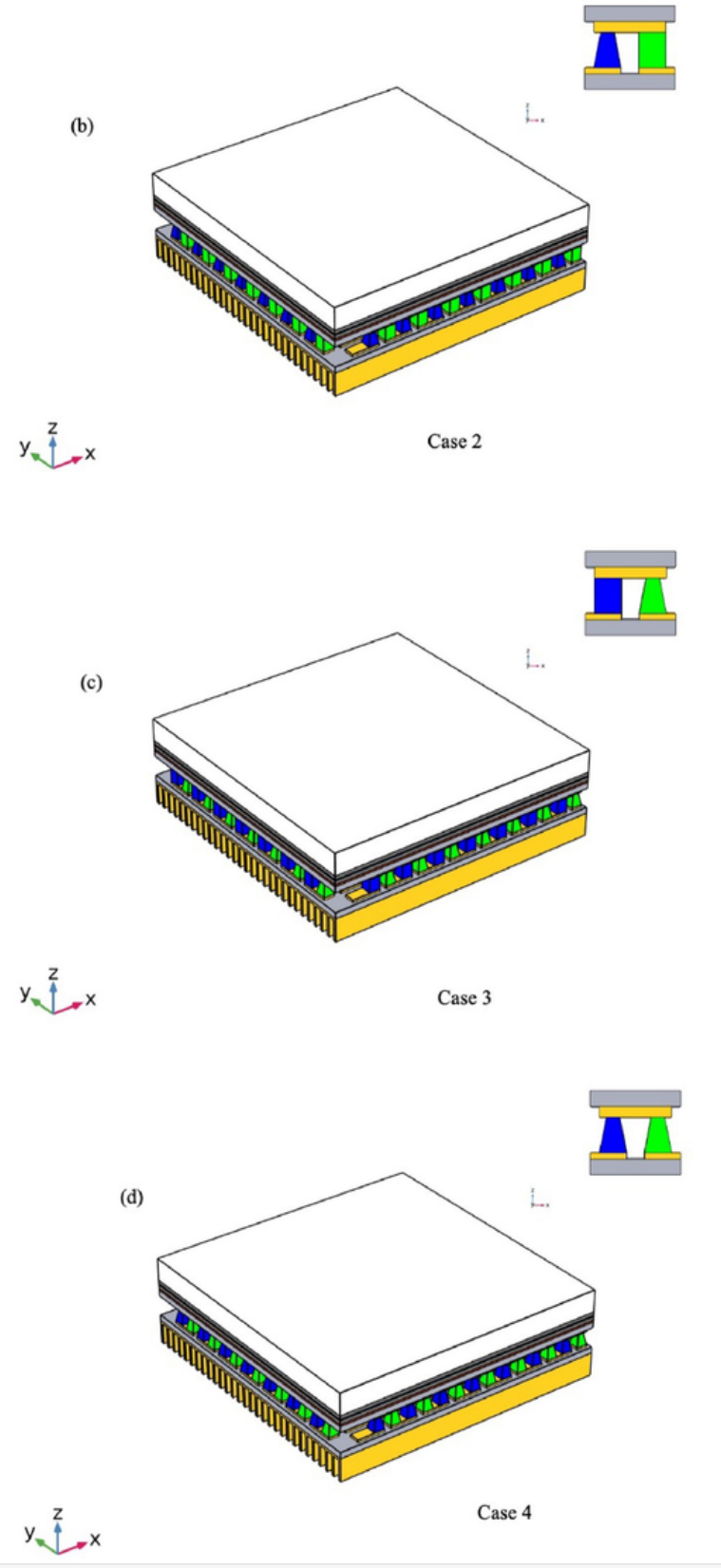


(i) The table layout displayed in this section is not how it will appear in the final version. The representation below is solely purposed for providing corrections to the table. To preview the actual presentation of the table, please view the Proof.

Hybrid system geometric parameters.

\begin{tabular}{|c|c|c|}
\hline Parameter & Base value & Reference \\
\hline \multicolumn{3}{|l|}{ Photovoltaic (PV) } \\
\hline Area & $40 \mathrm{~mm} \times 40 \mathrm{~mm}$ & {$[28]$} \\
\hline Glass thickness & $3.2 \mathrm{~mm}$ & {$[31]$} \\
\hline EVA thickness & $4.6 \times 10^{-1} \mathrm{~mm}$ & {$[31]$} \\
\hline Polycrystalline silicon thickness & $1.8 \times 10^{-1} \mathrm{~mm}$ & {$[31]$} \\
\hline TPT thickness & $1.8 \times 10^{-1} \mathrm{~mm}$ & {$[31]$} \\
\hline \multicolumn{3}{|l|}{ Thermoelectric generator (TEG) } \\
\hline Area & $40 \mathrm{~mm} \times 40 \mathrm{~mm}$ & {$[36]$} \\
\hline Leg area & $1.5 \mathrm{~mm} \times 1.5 \mathrm{~mm}$ & {$[36]$} \\
\hline Leg height & $1.96 \mathrm{~mm}$ & {$[36]$} \\
\hline Top copper thickness & $0.6 \mathrm{~mm}$ & {$[36]$} \\
\hline Lower copper thickness & $0.34 \mathrm{~mm}$ & {$[36]$} \\
\hline Ceramic thickness & $0.86 \mathrm{~mm}$ & {$[36]$} \\
\hline \multicolumn{3}{|l|}{ Heat sink } \\
\hline Area & $40 \mathrm{~mm} \times 40 \mathrm{~mm}$ & \\
\hline Height & $3.34 \mathrm{~mm}$ & \\
\hline Number of fins & 30 & \\
\hline Concentration ratio & 30 & [39] \\
\hline Heat sink heat transfer coefficient & $500 \mathrm{~W} / \mathrm{m}^{2} \mathrm{~K}$ & [39] \\
\hline
\end{tabular}

(i) The table layout displayed in this section is not how it will appear in the final version. The representation below is solely purposed for providing corrections to the table. To preview the actual presentation of the table, please view the Proof.

Thermoelectric material cubic polynomial functions [36].

\begin{tabular}{|c|c|c|}
\hline Property & p-type polynomial expression & n-type polynomial expression \\
\hline $\begin{array}{l}\text { Seebeck } \\
\text { coefficient } \\
(V / K)\end{array}$ & $-2.24407 \times 10^{-11} T^{3}+2.22834 \times 10^{-8} T^{2}-7.301 \times 10^{-6} T+1.023698 \times 10^{-3}$ & $1.68178 \times 10^{-11} T^{3}-1.77163 \times 10^{-8} T^{2}+6.203 \times 10^{-6} T-9.54589 \times 10^{-4}$ \\
\hline $\begin{array}{l}\text { Thermal } \\
\text { conductivity } \\
(W / m * K)\end{array}$ & $-5.82609 \times 10^{-8} T^{3}+1.03491 \times 10^{-4} T^{2}-0.05011 T+8.726$ & $3.76869 \times 10^{-9} T^{3}+2.81722 \times 10^{-5} T^{2}-0.02057 T+5.09531$ \\
\hline $\begin{array}{l}\text { Electrical } \\
\text { resistivity }\left(\Omega m^{2}\right)\end{array}$ & $-7.75456 \times 10^{-13} T^{3}+7.77051 \times 10^{-10} T^{2}-0.01853 \times 10^{-5} T+1.60117 \times 10^{-5}$ & $-6.04782 \times 10^{-13} T^{3}+6.09155 \times 10^{-10} T^{2}-1.715 \times 10^{-7} T+2.11951 \times 10^{-5}$ \\
\hline
\end{tabular}

Furthermore, Fig. 1a shows the schematic of the hybrid system with symmetrical n-type and p-type thermoelectric leg geometry which corresponds to Case 1. Fig. 1 b corresponds to Case 2 which is asymmetrical n-type and symmetrical p-type thermoelectric leg geometry. Similarly, Case 3 shown in Fig. 1c corresponds to symmetrical p-type and asymmetrical n-type TE leg geometry. Lastly, Case 4 shown in Fig. 1d is the hybrid system with asymmetrical n-type and p-type TE leg geometry. In all the cases, the leg dimensions are equal. However, the asymmetrical leg is obtained by the variation of cross-sectional area along the height of the thermoelectric leg. Therefore, the hot side (top) cross-sectional area of the asymmetrical leg is half that of the cold side (bottom). Between the thermoelectric legs and 
copper electrodes, thermoelectric electrical contact resistance is considered while thermoelectric thermal contact resistance is considered between the ceramic plates and copper electrodes. Furthermore, thermal contact resistance is considered between the tedlar and ceramic top surface, and between the ceramic lower surface and heat sink. The values of the thermoelectric electrical and thermal contact resistance are $6.5 \times 10^{-9} \Omega \mathrm{m}^{2}$ and $2 \times 10^{-4} \mathrm{~m}^{2} \mathrm{~K} / \mathrm{W}$ respectively [26]. The values of the other two thermal contact resistance are $2 \times 10^{-4} \mathrm{~m}^{2} \mathrm{~K} / \mathrm{W}$ each [27].

\section{Numerical model and validation}

This section presents the photovoltaic, thermoelectric generator and hybrid system models used in the numerical study. The photovoltaic and thermoelectric generator are modelled separately initially before they are integrated to form the hybrid photovoltaic-thermoelectric system. Furthermore, the boundary conditions applied to the numerical model and the validation of the model are presented.

\subsection{Photovoltaic model}

Temperature distribution in the layers of the photovoltaic are obtained using the three-dimensional energy equation below [28,29]:

$$
\rho_{d} C_{p} \frac{\partial T}{\partial t}-\nabla \cdot(\kappa \nabla T)=q_{s o l}-P_{g e n}
$$

where $\rho_{d}, \kappa$ and $C_{p}$ are respectively the density, thermal conductivity and specific heat capacity of each layer. Furthermore, $q_{s o l}$ is the volumetric solar energy absorption, $T$ is temperature and $P_{g e n}$ is the power generation from the polycrystalline silicon layer and is zero for all other layers.

In each layer of the photovoltaic, the volumetric solar energy absorption is modelled as an internal heat generation and expressed as,

$$
q_{s o l, i}=\frac{G_{r e c, i} \times \alpha_{i} \times A_{i} \times C}{V_{i}}
$$

$$
G_{r e c, i}=G_{r e c, i-1} \times\left[\left(1-\alpha_{i-1}\right)-\rho_{i-1}\right]
$$

where $C$ is solar concentration ratio, $\rho_{i}, V_{i}$ and $\alpha_{i}$ are respectively the reflectivity, volume and absorptivity of the ith layer. Furthermore, $G_{r e c, i}$ and $A_{i}$ are respectively the solar radiation intensity, and area of each layer while.

Power generation and efficiency of the silicon cell layer is given as [30]:

$$
P_{\text {gen }}=q_{s o l, 3} \times \eta_{p v}
$$

$\eta_{p v}=\eta_{r e f}\left[1-\beta\left(T_{p v}-T_{r e f}\right)\right]$

where $T_{\text {ref }}, \eta_{\text {ref }} \beta$ are respectively the reference temperature (298.15K), reference efficiency (17\%) and temperature coefficient (0.00451/K) [31]. Furthermore, $\eta_{p v}$ is photovoltaic efficiency and $q_{s o l, 3}$ is volumetric solar energy absorption at the silicon cell layer. The coupled thermal and electrical equations are solved simultaneously using finite element method.

Heat loss due to radiation is considered at the glass top surface of the photovoltaic and it is given as $[32,33]$ :

$$
h_{r a d}=\varepsilon \sigma\left(T_{p v}^{2}+T_{s k y}^{2}\right)\left(T_{p v}+T_{s k y}\right)
$$

where $\sigma$ is the Stefan-Boltzmann constant, $\varepsilon$ is emissivity and $T_{s k y}$ is sky temperature which is given as [34]:

$$
T_{s k y}=0.0552 T_{a}^{1.5}
$$

where $T_{a}$ is the temperature of the ambient.

In the hybrid system, convective heat loss is considered only at the top glass layer of the photovoltaic. Heat transfer coefficient for convective heat loss is given as [ 22]: 
where $v$ is wind speed $(\mathrm{m} / \mathrm{s}), h_{c o n v, t}$ and $h_{\text {conv, },}$ are respectively, the convective heat transfer coefficient at the top glass layer and bottom tedlar layer.

\subsection{Thermoelectric generator model}

Heat transfer and electric current governing equations can be expressed as vectors [25]:

$$
\vec{\nabla} \cdot \vec{J}=0
$$

$$
-\vec{\nabla} \cdot \overrightarrow{\mathrm{q}}+\dot{Q}=0
$$

where $\overrightarrow{\mathrm{J}}$ is the vector of the electric current density and $\overrightarrow{\mathrm{q}}$ is the reversible heat transfer due to the Peltier effect and using Fourier's law, it is given as,

$$
\overrightarrow{\mathrm{q}}=\alpha \overrightarrow{\mathrm{J}}-\kappa \vec{\nabla} T
$$

Combining the Seebeck and Ohm effects, the electric field density $\overrightarrow{E_{f}}$ at any location is given as,

$$
\overrightarrow{E_{f}}=\alpha \Delta \overrightarrow{\mathrm{T}}+\rho \overrightarrow{\mathrm{J}}
$$

Power generated per unit volume $\dot{Q}$ is given as,

$$
\dot{Q}=\overrightarrow{E_{f}} \cdot \overrightarrow{\mathrm{J}}
$$

Temperature distribution inside the thermoelectric generator is obtained by combining the equations above and it is given as,

$$
\vec{\nabla} \cdot(\kappa \vec{\nabla} T)+\rho \overrightarrow{\mathrm{J}} \cdot \overrightarrow{\mathrm{J}}-T \frac{d \alpha}{d T} \vec{\nabla} T \cdot \overrightarrow{\mathrm{J}}=0
$$

where $T \frac{d \alpha}{d T}$ is the Thomson coefficient, $\rho, \alpha$ and $\kappa$ are electrical resistivity, Seebeck coefficient and thermal conductivity respectively.

Electric power generated by the thermoelectric generator is given as,

$$
P_{\text {teg }}=\left(\frac{V_{o c}}{R_{\text {in }}+R_{L}}\right)^{2} \cdot R_{L}
$$

Thermoelectric generator efficiency is given as,

$$
\eta_{\text {teg }}=\frac{P_{\text {teg }}}{Q_{h}}
$$

where $V_{o c}$ is open circuit voltage, $R_{i n}$ is internal resistance, $R_{L}$ is external load resistance and $Q_{h}$ is input power at thermoelectric generator top surface.

\subsection{Hybrid system model}

The power output of the hybrid system is given as [35],

$P_{c p v_{-} t e}=P_{g e n}+P_{t e g}$ 


\subsection{Boundary conditions}

To simply the model without much deviation from the actual reality, the following assumptions are made.

\subsection{Transient conditions are assumed in this study}

2. The initial temperature of the system is assumed to be equal to the ambient temperature.

3. For radiative heat loss calculation, the PV top glass surface is taken to view the sky while the bottom tedlar surface is taken to view ground/ambient.

4. Adiabatic conditions are assumed on the side surfaces of the thermoelectric generator.

5. Convective heat transfer coefficient is used to model the TEG cooling with heat sink.

\subsection{Model validation}

To ensure the simulation results from this study are independent of mesh size, in-built COMSOL 5.4 Multiphysics mesh settings are used for performing the mesh convergence test. Table 3 shows the results obtained from using four different mesh element size. Considering Case 1, the number of domain elements corresponding to the element size coarser, coarse, normal and fine are 70,623, 138,103, 297,623 and 670,194 respectively. For Case 2, the number of domain elements for coarser, coarse, normal and fine are 73,608, 139,413, 301,738 and 660,513 respectively. Furthermore, considering Case 3, the number of domain elements for coarser, coarse, normal and fine are 73,669, 139,473, 301,990 and 660,808 respectively. While for Case 4, the number of elements for coarser, coarse, normal and fine are $77,664,138,348,305,800$ and 656,278 respectively. As shown in Table 3, the power density of the hybrid system and average photovoltaic cell temperature for the different cases converge when the Normal mesh is used. However, to obtain a more accurate result, the Fine mesh is used for all cases throughout this study.

alt-text: Table 3

Table 3

(i) The table layout displayed in this section is not how it will appear in the final version. The representation below is solely purposed for providing corrections to the table. To preview the actual presentation of the table, please view the Proof.

Mesh convergence test for hybrid system with different geometries.

\begin{tabular}{|c|c|c|c|c|c|c|c|c|}
\hline \multirow[t]{2}{*}{ Element size } & \multicolumn{4}{|c|}{ Hybrid power density $\left(\mathrm{W} / \mathrm{m}^{3}\right)$} & \multicolumn{4}{|c|}{ Average $P V$ cell temperature (K) } \\
\hline & Case 1 & Case 2 & Case 3 & Case 4 & Case 1 & Case 2 & Case 3 & Case 4 \\
\hline Coarser & $6.76942 \mathrm{E} 6$ & $5.92968 \mathrm{E} 6$ & $5.95489 \mathrm{E} 6$ & $4.89517 \mathrm{E} 6$ & 433.92 & 447.7 & 446.92 & 467.34 \\
\hline Coarse & $6.76865 \mathrm{E} 6$ & $5.9276 \mathrm{E} 6$ & $5.95348 \mathrm{E} 6$ & $4.89271 \mathrm{E} 6$ & 433.93 & 447.73 & 446.94 & 467.38 \\
\hline Normal & $6.76717 \mathrm{E} 6$ & $5.92517 \mathrm{E} 6$ & $5.95096 \mathrm{E} 6$ & $4.88711 \mathrm{E} 6$ & 433.95 & 447.77 & 446.98 & 467.49 \\
\hline Fine & $6.76717 \mathrm{E} 6$ & $5.92517 \mathrm{E} 6$ & $5.95096 \mathrm{E} 6$ & $4.88711 \mathrm{E} 6$ & 433.95 & 447.77 & 446.98 & 467.49 \\
\hline
\end{tabular}

Furthermore, the photovoltaic model is validated with result of Motiei et al. [22] as shown in Fig. 2a while the thermoelectric generator model is validated with result of He et al. [36] which is shown in Fig. 2b. For both validations, the referenced simulation conditions are used, and the accuracy of the models used in this study are tested. From Fig. 2a and b it is very clear that the numerical models for the photovoltaic and thermoelectric generator used in this study are accurate and results from this study are reliable because of the very good agreement of the models with the referenced literatures during validation. 

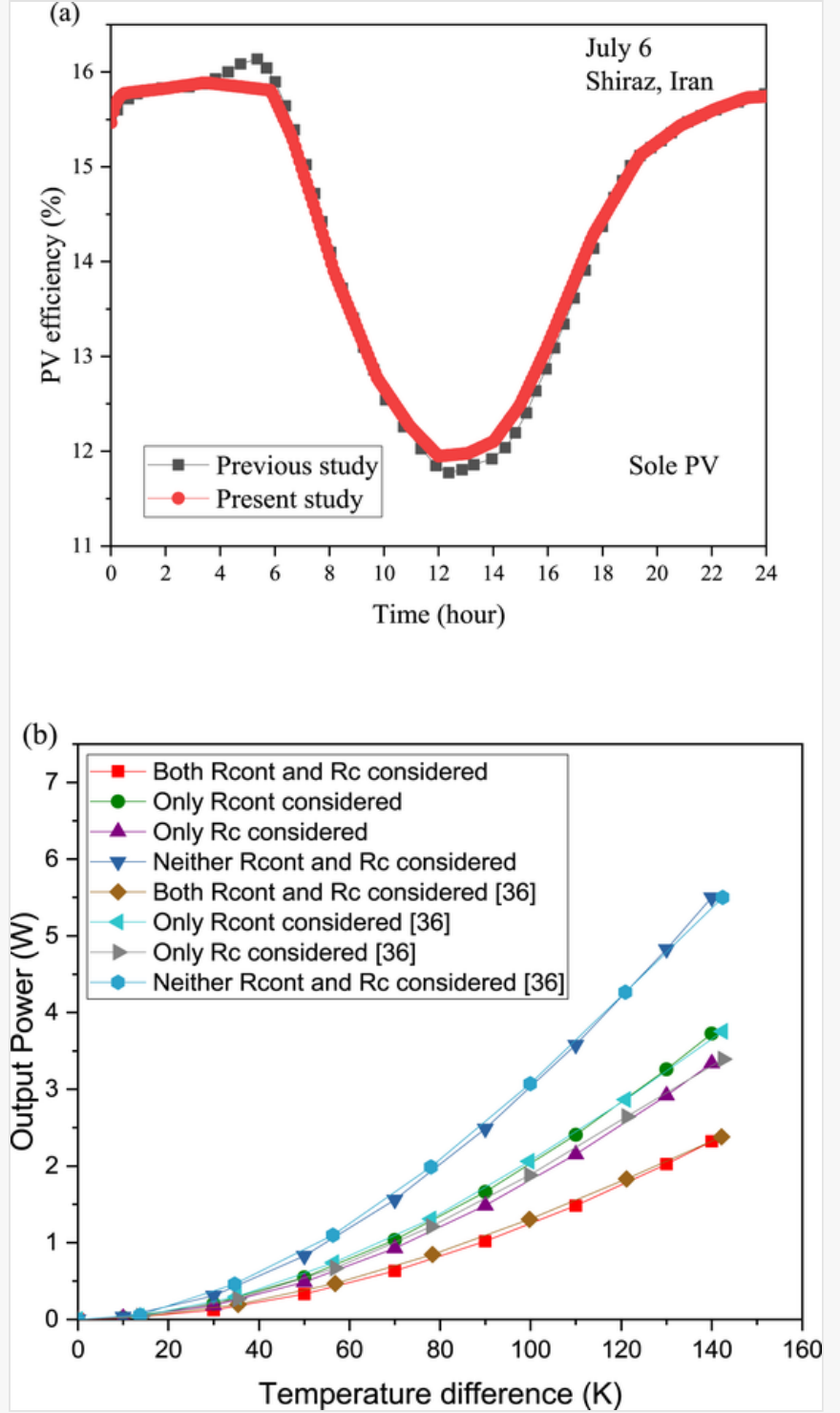

Photovoltaic model validation with [22] and thermoelectric generator model validation with [36].

\section{Results and discussion}

Actual variable weather conditions are considered in this study for summer climatic conditions in Heathrow, Greater London, United Kingdom for July 2, 2017. The computation is run for $24 \mathrm{~h}$ (one-day). The hourly solar radiation data is obtained from Ref. [37] and shown in Fig. 3a while the hourly ambient temperature and wind speed are obtained from Ref. [38] and shown in Fig. 3b. Furthermore, since this study involves the comparison of different thermoelectric leg geometries, the power output parameter will be expressed per volume as power output density to enable an adequate balance of material volume for the different leg geometries. Therefore, the power output density for the thermoelectric generator is given as,

$$
P_{\text {den } \_ \text {teg }}=\frac{P_{\text {teg }}}{V_{\text {legs }}}
$$



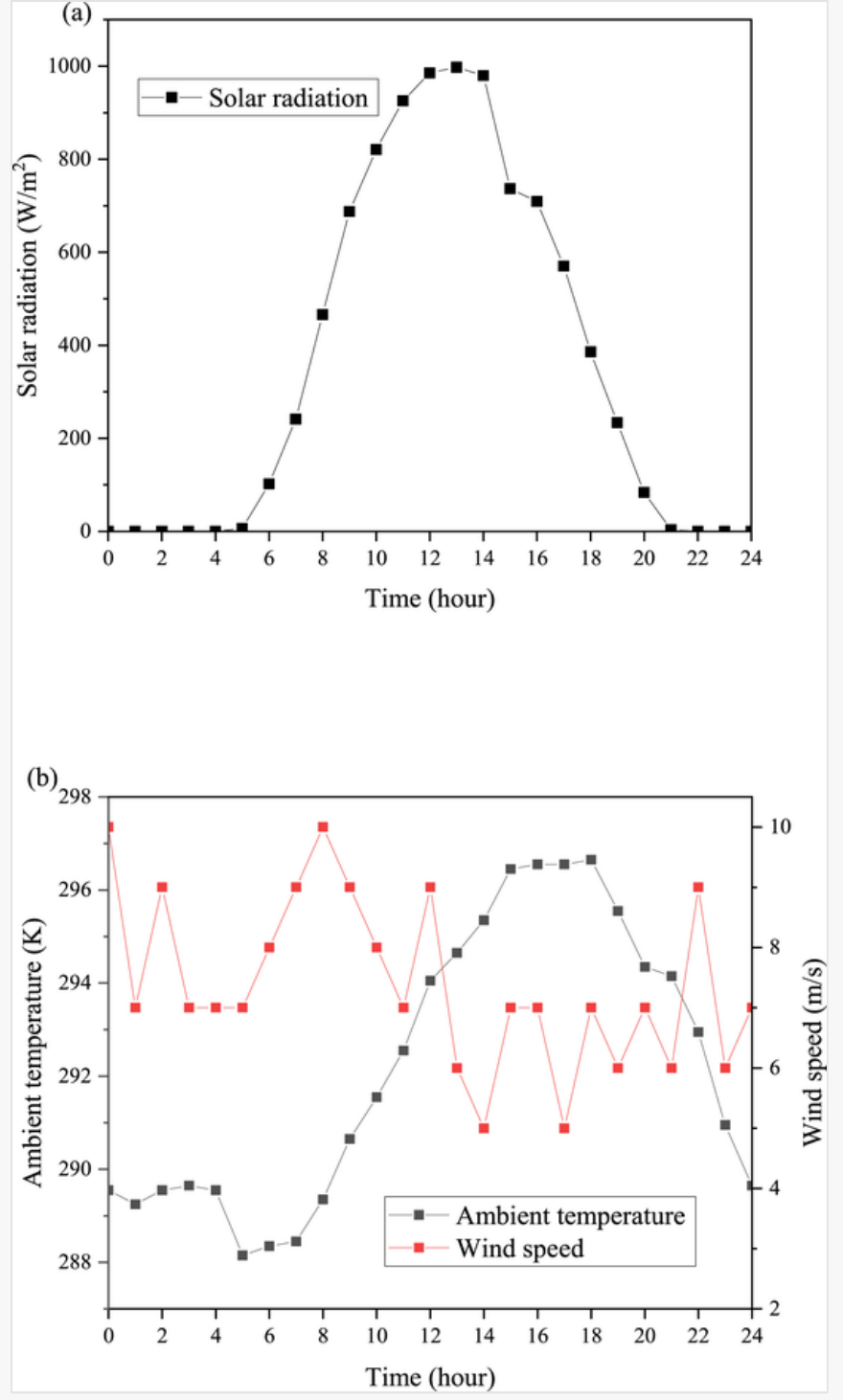

Hourly weather data (a) solar radiation [37] and (b) ambient temperature and wind speed [38].

Similarly, power output density will be used to describe the power performance of the photovoltaic and it is given as,

$$
P_{\text {den } \_v}=\frac{P_{g e n}}{V_{p v}}
$$

where $V_{\text {legs }}$ is the total volume of the thermoelectric legs and $V_{p v}$ is the volume of the PV silicon cell layer.

Therefore, the power output density of the hybrid system is given as,

$P_{\text {den_cpv_te }}=P_{\text {den_p } p}+P_{\text {den_teg }}$

Fig. 4 shows the volume of the thermoelectric legs considered for the parametric study. It can be seen from Fig. 4a that when the cross-sectional area is constant, the volume of the thermoelectric legs increases as the leg height increase. A similar trend is observed when the leg height is kept constant and area is varied as shown in Fig. 4b. It is also clear from Fig. 4 that the thermoelectric geometry in Case 1 has the highest volume while Case 4 has the lowest value and the volume of Case 2 and Case 3 are exactly the same.

alt-text: Fig. 4 

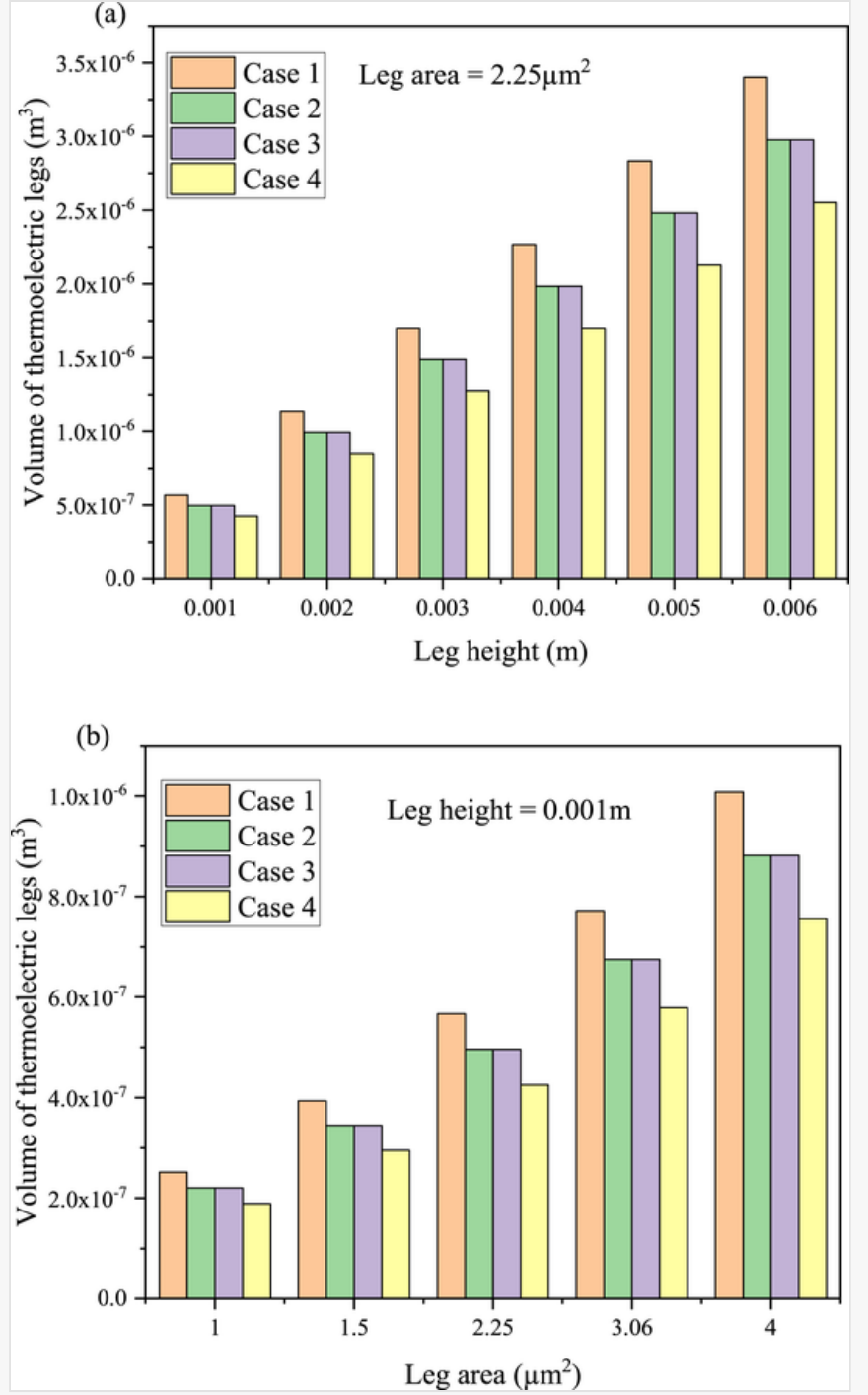

Total thermoelectric legs volume for different (a) leg height and (b) leg area.

\subsection{Effect of thermoelectric leg height and area}

The height and cross-sectional area of thermoelectric legs significantly affect the thermoelectric generator performance. Therefore, the effect of thermoelectric leg height on the performance of the hybrid CPV-TE is shown in Fig. 5 using the base values at a peak time of 13:00pm. It can be seen from Fig. 5a that the temperature of the concentrated photovoltaic cell in the hybrid system significantly increases linearly as the leg height is increased. This implies that long thermoelectric legs reduce the heat removal capacity of the thermoelectric generator which is attached to the concentrated photovoltaic. Furthermore, from Fig. $5 \mathrm{a}$, it can be seen that the CPV-TE system with a thermoelectric geometry of Case 4 has the highest CPV cell temperature while Case 1 provides the lowest CPV cell temperature. Consequently, it is clear that in a hybrid CPV-TE, the asymmetrical n-type and p-type thermoelectric leg geometry (Case 4) provides the worst heat removal performance. 
type thermoelectric legs (Case 1) is better for the CPV-TE system. This shows the importance of geometry optimization as the optimum geometry in a thermoelectric generator is not necessarily the same as that in a hybrid CPV-TE system.

The effect of thermoelectric leg area on the hybrid system performance for an optimum leg height of $1 \mathrm{~mm}$ is shown in Fig. 6 for a peak time of 13:00pm. Firstly, Fig. 6a shows that the CPV cell temperature decrease almost linearly as the leg area increased which in turn leads to an increase in the CPV-TE power output density. It can also be seen that although the CPV cell temperature decreases with an increase in leg area, Case 4 geometry still provides the highest values while Case 1 provides the lowest values. Case 2 and Case 3 provide very similar results as the geometries are very similar. Since the thermoelectric generator area $(40 \mathrm{~mm} \times 40 \mathrm{~mm})$ is kept constant, the increase in leg area simply means a decrease in the leg spacing. Although the thermoelectric legs volume increase as the leg area is increased, Fig. 6a shows that the hybrid system power output density still increases. The power output density is an important parameter because it considers the volume of material used. When the leg area increased from $1 \mu \mathrm{m}^{2}$ to $4 \mu \mathrm{m}^{2}$, the CPV cell temperature for Case 1, Case 2, Case 3 and Case 4 decreased by $10.46 \%, 12.42 \%, 12.30 \%$ and $14.93 \%$ respectively. Furthermore, at the optimum leg area of $4 \mu \mathrm{m}^{2}$, the hybrid system power output density for Case 1 is higher than that of Case 2, Case 3 and Case 4 by $4.44 \%, 4.27 \%$ and $11.55 \%$ respectively.

alt-text: Fig. 6

Fig. 6
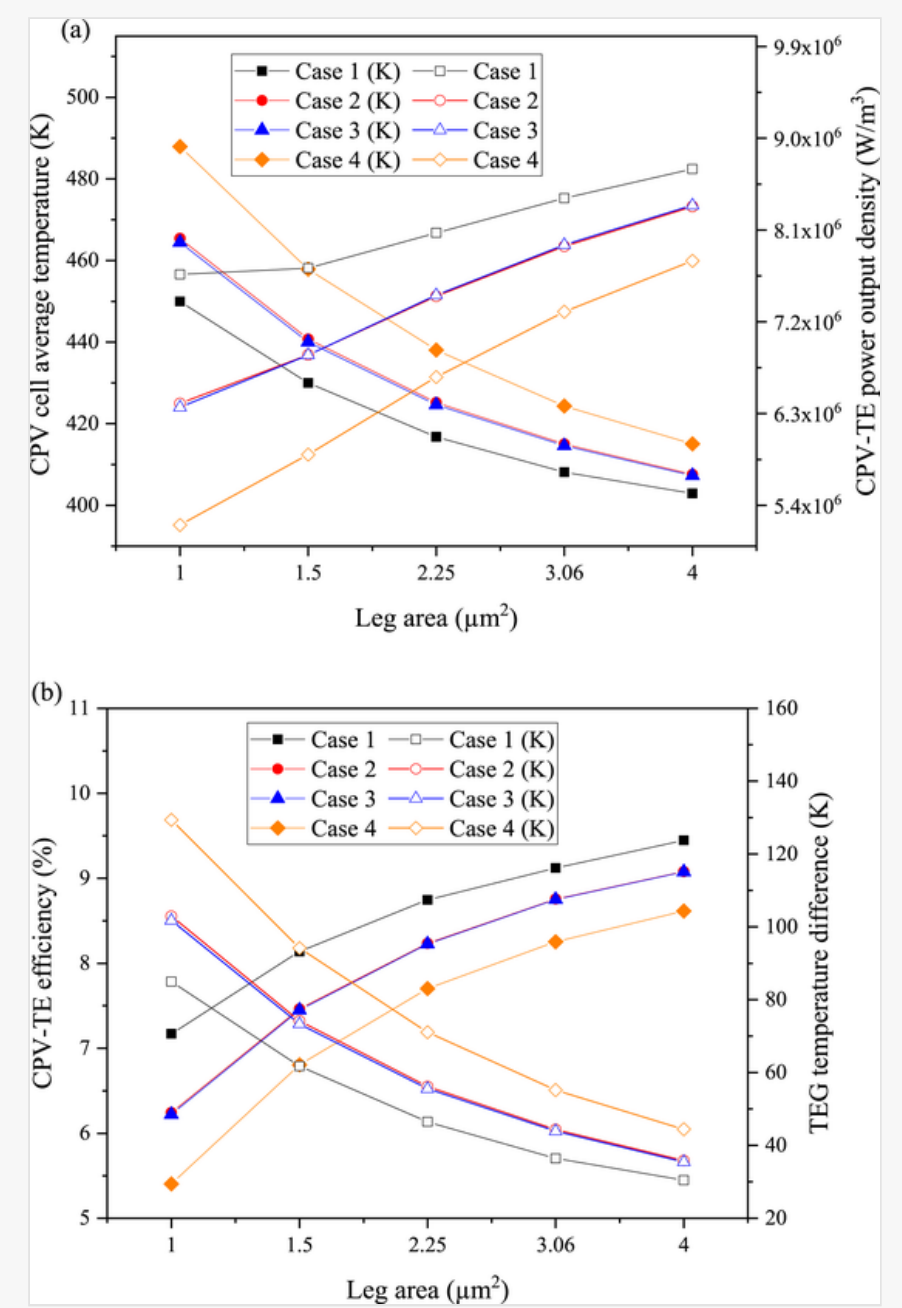

Leg area variation with (a) CPV cell temperature, CPV-TE power output density and (b) CPV-TE efficiency, temperature difference.

Fig. $6 \mathrm{~b}$ shows the CPV-TE efficiency variation with leg area and the thermoelectric generator temperature difference. Furthermore, it is obvious that the efficiency of the CPV-TE increases as the leg area increase while Case 2 and Case 3 provide identical efficiency values and Case 1 provides the highest hybrid system efficiency. In addition, Fig. $6 \mathrm{~b}$ shows that Case 4 provides the highest thermoelectric generator temperature difference for all leg areas while Case 1 provides the lowest temperature difference. The reason for this is that the asymmetrical leg geometry provides a decrease in the overall TEG thermal conductance, which causes a higher temperature difference to be built across the thermoelectric generator, which in turn leads to a higher CPV cell temperature as shown in Fig. 6a. Consequently, Case 4 would provide enhanced TEG only performance because of its higher temperature difference compared to the others however, it is not suitable for the hybrid system.

\subsection{Effect of ceramic height}

Asides the thermoelectric leg height and area, the ceramic height of the thermoelectric generator is another important that significantly affects the TEG performance. This is because, the ceramic is used to enhance thermal concentration in the thermoelectric generator. Fig. 7 shows the performance of the CPV-TE for an optimum leg height of $1 \mathrm{~mm}$ and leg area of $4 \mu \mathrm{m}^{2}$ at a peak time of 13:00pm. Furthermore, Fig. 7a presents the variation of thermoelectric ceramic height with CPV cell temperature and CPV-TE power output density. The CPV cell temperature increase as the ceramic height increase can be seen clearly. The reason for this is that the long ceramic height/thickness decrease the amount of heat transferred to the cold side of the TEG through the thermoelectric legs. Thus, for a hybrid CPV-TE, short thermoelectric ceramic height is beneficial. Furthermore, it can be seen from Fig. 7a that the CPV cell temperature for Case 1 is significantly lower than the others. It can also be seen that the ceramic height variation reduces the CPV cell temperature more for Case 3 compared to Case 2 although the results are closely related. The decrease of CPV-TE power output density with ceramic height increase can be seen in Fig. 7a. At an optimum ceramic height of $0.2 \mathrm{~mm}$, the CPV-TE power output density for Case 1 is greater than that of Case 2, Case 3 and Case 4 by 3.90\%, 3.72\% and 10.21\% respectively. 

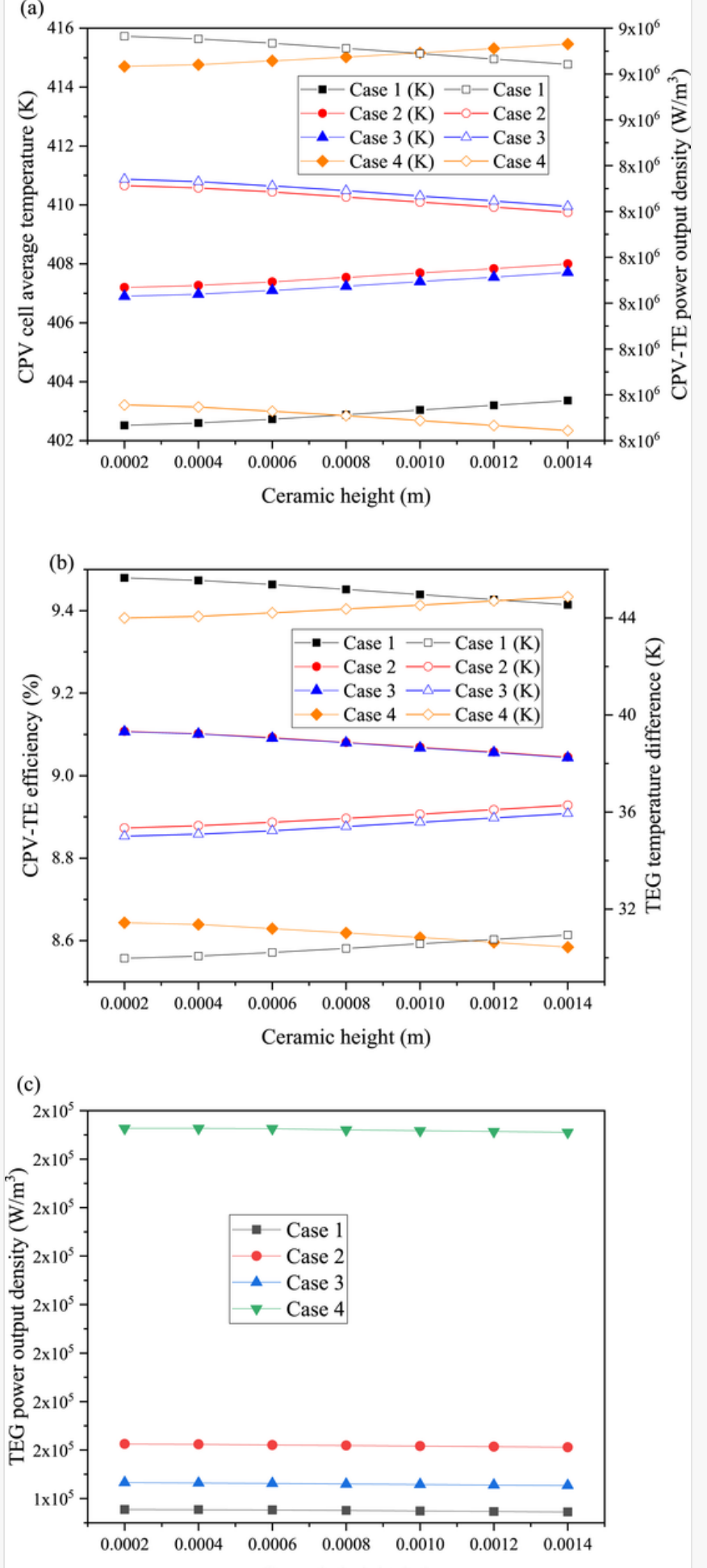

Variation of ceramic height with (a) CPV cell temperature, CPV-TE power output density (b) CPV-TE efficiency, temperature difference and (c) TEG power output density.

Similarly, Fig. $7 \mathrm{~b}$ shows the hybrid system efficiency using Case 1 is the highest while that of Case 4 is the lowest. In addition, it is clear that the efficiency of the hybrid system decreases as the ceramic height increases although the thermoelectric generator temperature difference is increased. This is because of the increased thermal concentration obtained by the increase in ceramic height which leads to an increase in temperature difference. Furthermore, Fig. $7 \mathrm{c}$ shows the power output density of the thermoelectric generator in the CPV-TE. It can be seen clearly that the highest TEG power output density is obtained from Case 4 followed by Case 2 , Case 3 and the lowest is obtained from Case 1. This echoes the observation that asymmetrical n-type and p-type thermoelectric legs (Case 4) significantly enhance the TEG only performance. Basically, the asymmetrical geometry provides enhanced TEG performance compared to the symmetrical geometry although the reverse is the case when the CPV is integrated to form a hybrid CPV-TE system.

\subsection{Effect of convective cooling and thermoelectric geometry optimization}

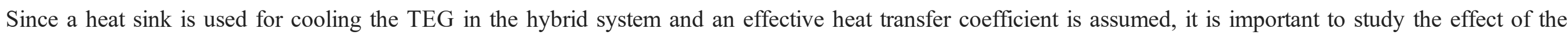

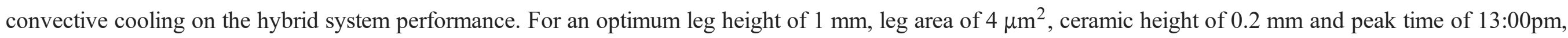

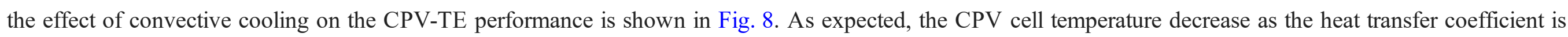

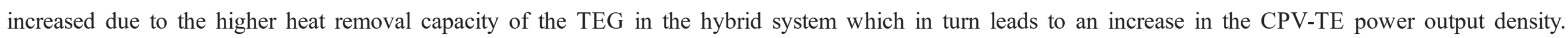

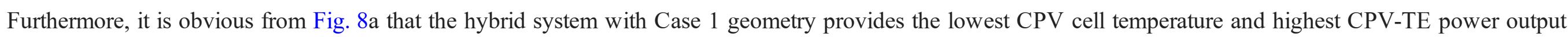

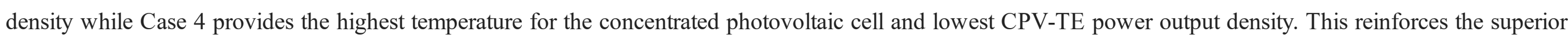

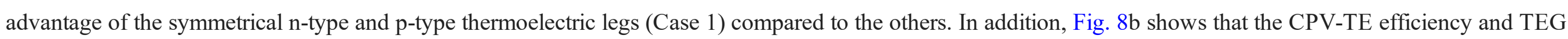

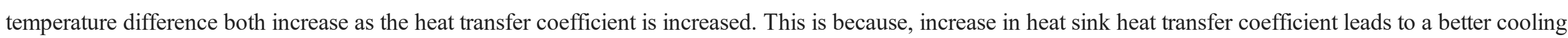

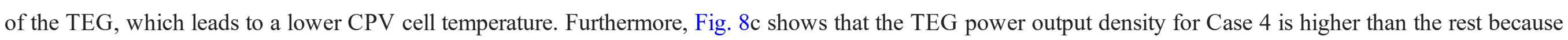
of the asymmetrical n-type and p-type geometry which enhances TEG performance. 

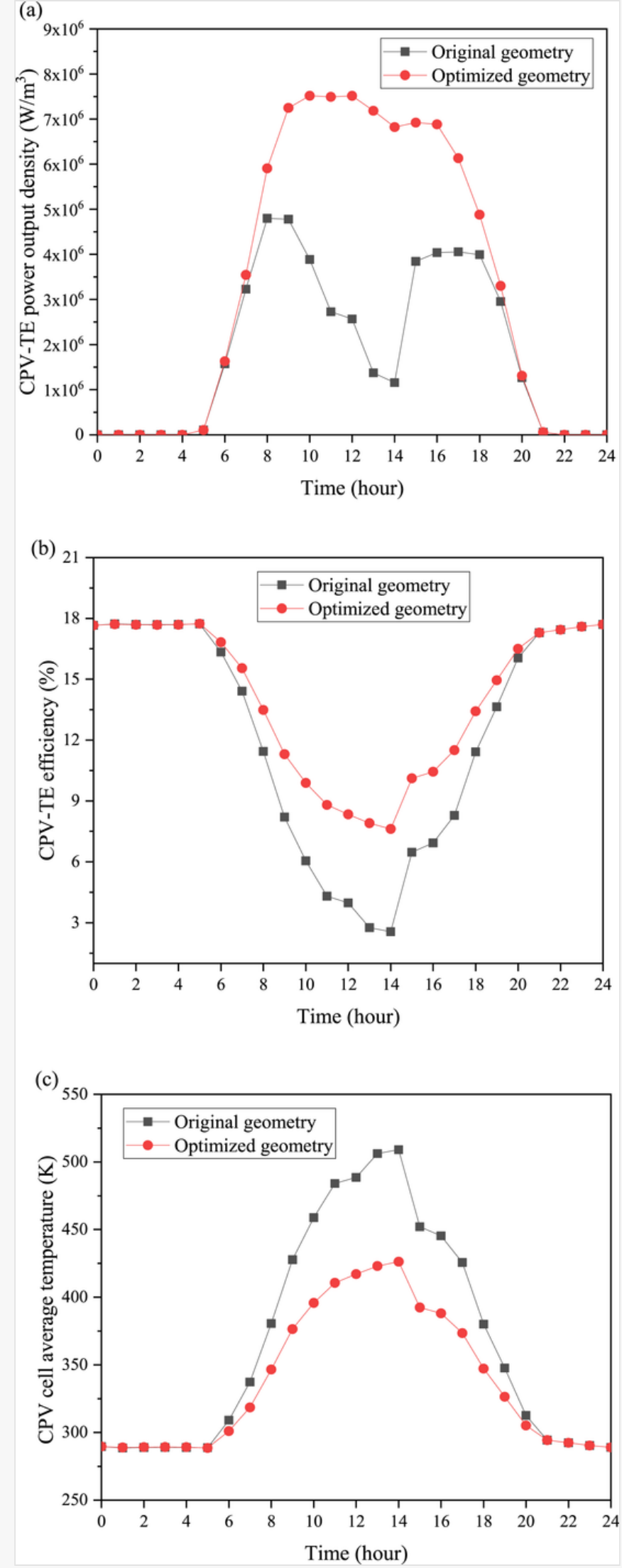

Variation of time with CPV-TE (a) power output density (b) efficiency and (c) CPV cell temperature.

\subsection{Three-dimensional temperature and voltage distributions}

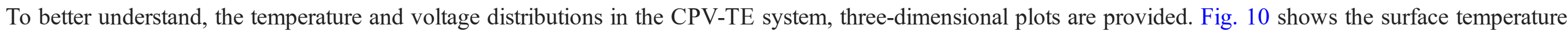

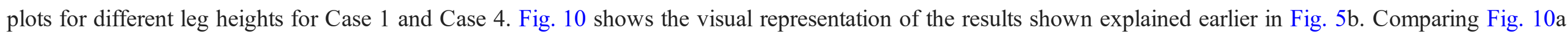

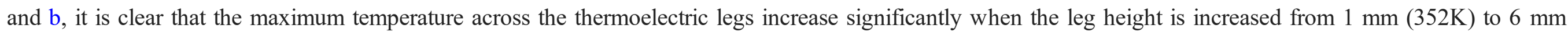

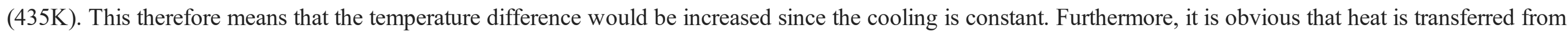

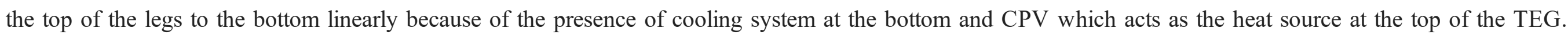

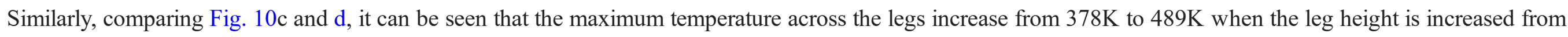

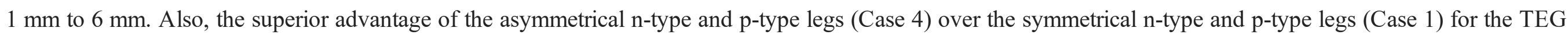

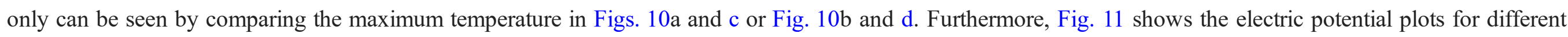

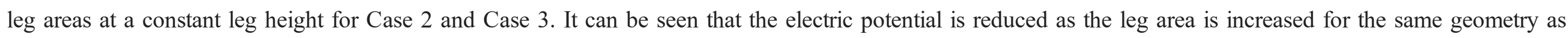
shown in Fig. 11a and b. In addition, Figs. 11c and d show that the electric potential decreases along the electrical series connected thermoelectric legs. 


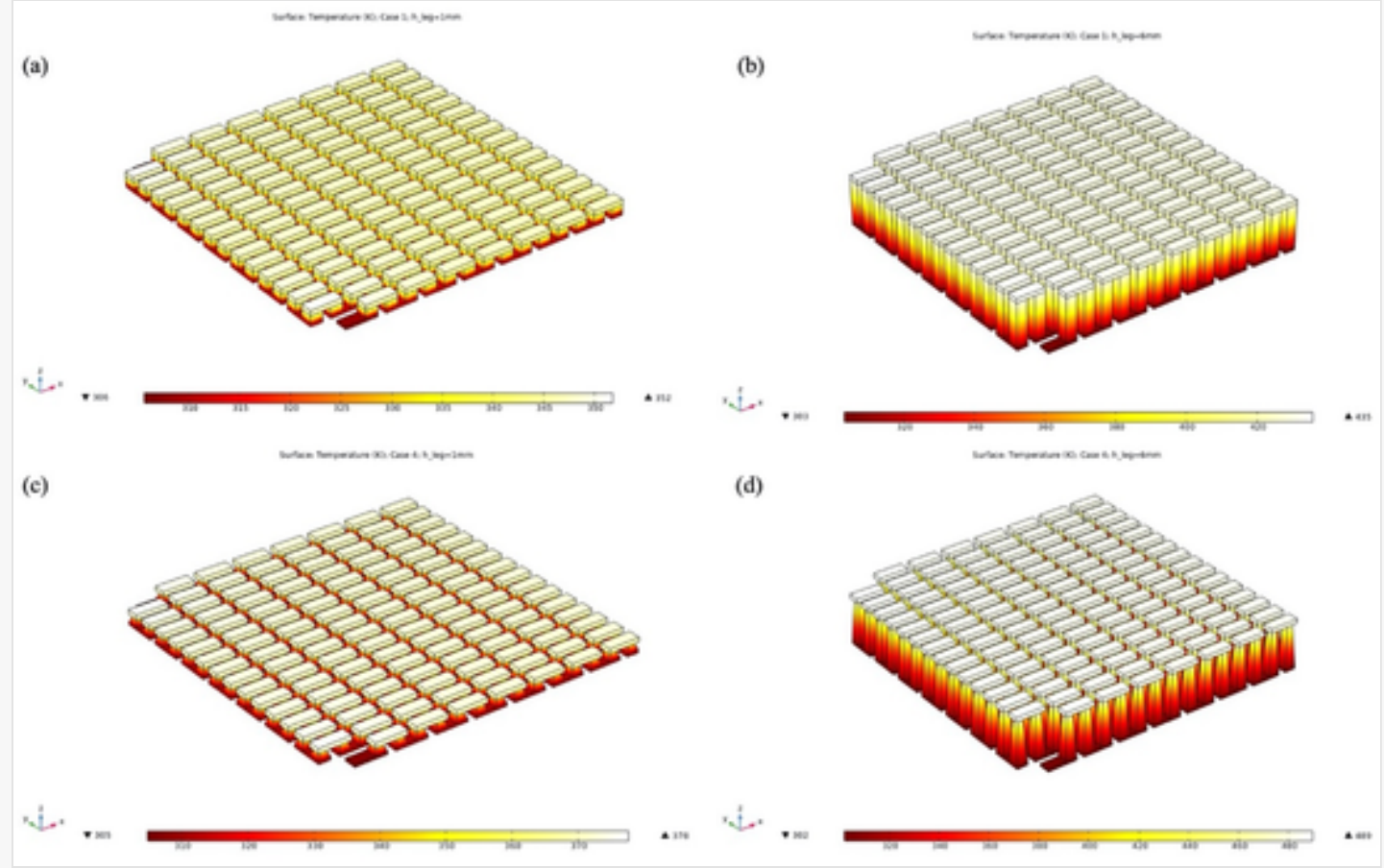

Surface temperature plots for leg height of (a, c) $1 \mathrm{~mm}$ and (b, d) $6 \mathrm{~mm}$.

alt-text: Fig. 11

Fig. 11
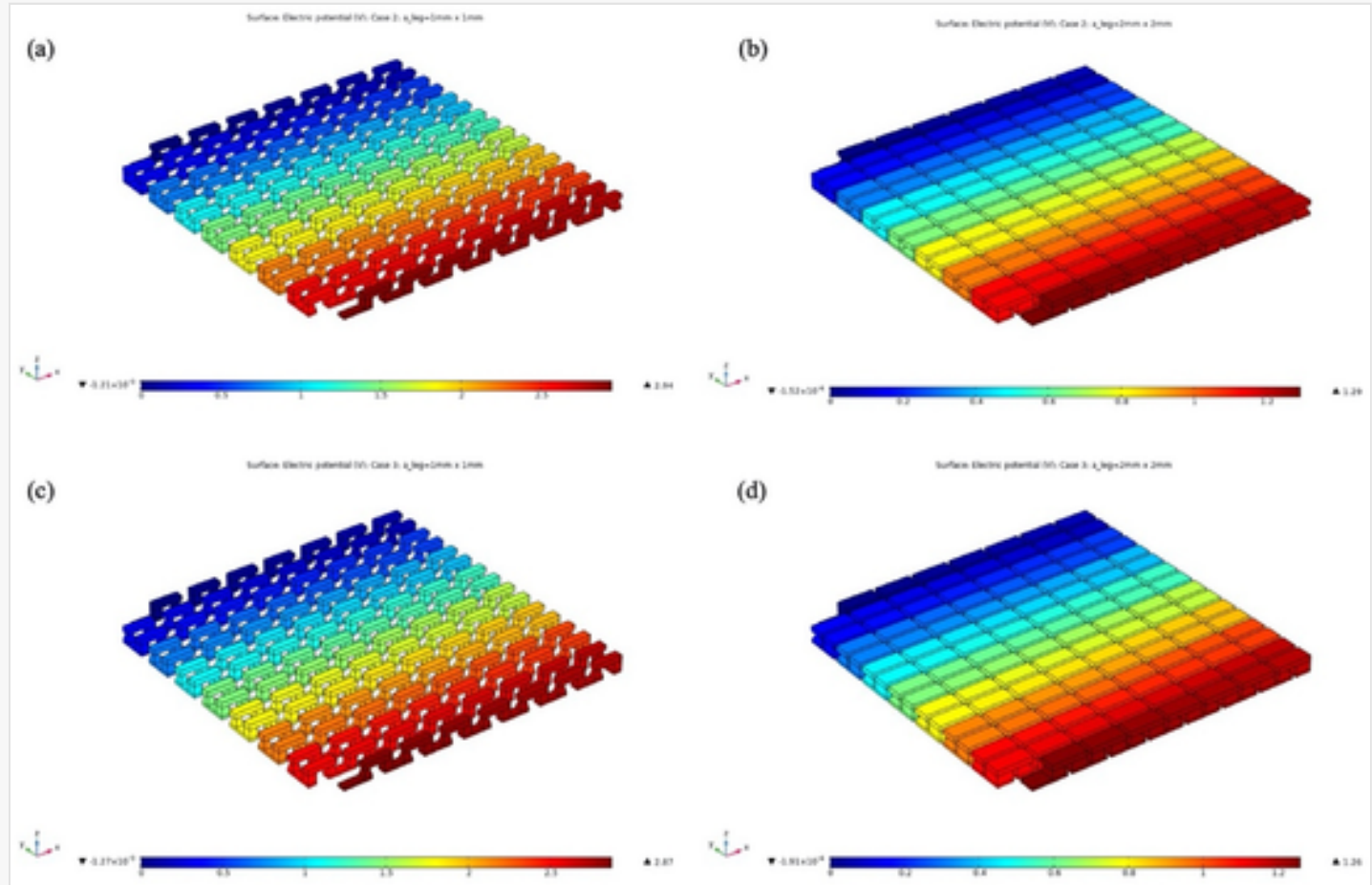

Electric potential plots for leg area of (a, c) $1 \mathrm{~mm}^{2}$ and (c, d) $4 \mathrm{~mm}^{2}$.

Fig. 12 presents the temperature distribution plots in three-dimension for the Case 1 CPV-TE with original geometry and optimized geometry at a peak time of 13:00pm. The hybrid system with original geometry can be seen in Figs. 12a and b while that with optimized geometry is shown in Fig. 12c and d. It is important to note that in this study, only the thermoelectric geometry is optimized and not the photovoltaic geometry as it is out of the scope of this particular study. Comparing Figs. 12a and $\mathrm{c}$ it can be seen that the maximum temperature in the hybrid system with original geometry is higher than that with optimized geometry. Figs. 12b and $\mathrm{d}$ show respectively the original and optimized TEG geometry in the hybrid system. Comparing both figures, it can be seen that the ceramic height/thickness in the optimized geometry (Fig. 12d) is lower than that in the original geometry (Fig. 12b). In addition, it can be seen that the leg height and leg area in the optimized geometry are lower and higher respectively compared to that in the original geometry. Consequently, the optimized thermoelectric geometry in the hybrid system in this study is obtained when the leg height is $1 \mathrm{~mm}$, leg area is $4 \mu \mathrm{m}^{2}$ and ceramic height is $0.2 \mathrm{~mm}$. 
Bottom tedlar layer convective heat transfer coefficient, $\mathrm{W} / \mathrm{m}^{2} \mathrm{~K}$

Top glass layer convective heat transfer coefficient, $\mathrm{W} / \mathrm{m}^{2} \mathrm{~K}$

Radiative heat loss, $\mathrm{W} / \mathrm{m}^{2}$

CPV-TE power output, $\mathrm{W}$

CPV-TE power output density, $\mathrm{W} / \mathrm{m}^{3}$

$\mathrm{PV}$ power generation, $\mathrm{W}$

TEG power output, $\mathrm{W}$

TEG input power, $\mathrm{W}$

Volumetric solar energy absorption, $\mathrm{W} / \mathrm{m}^{3}$

Internal resistance, $\Omega$

Load resistance, $\Omega$

Temperature, $\mathrm{K}$

Total volume of TE legs

Open circuit voltage, $\mathrm{V}$

\section{Greek symbols}

$\alpha$

$\sigma:$

$\kappa:$

$\beta$

\section{Abbreviations}

CPV:

CPV-TE:

TEG:

TPT:

Seebeck coefficient, V/K

Efficiency

Electrical conductivity, S/m

Thermal conductivity, $\mathrm{W} / \mathrm{mK}$

Temperature coefficient, $1 / \mathrm{K}$

Concentrated photovoltaic

Concentrated photovoltaic-thermoelectric

Thermoelectric generator

Tedlar polyester tedlar

\section{Subscripts}

a:

pv:

sky:

Ambient

Photovoltaic

Sky

\section{References}

(i) The corrections made in this section will be reviewed and approved by a journal production editor. The newly added/removed references and its citations will be reordered and rearranged by the production team.

[1] Shittu S., Li G., Zhao X., Ma X., Akhlaghi Y.G., Ayodele E. High performance and thermal stress analysis of a segmented annular thermoelectric generator. Energy Convers Manag 2019;184:180-193. doi:10.1016/j.enconman.2019.01.064.

[2] Li G., Ma X., Shittu S., Zhao X. Solar thermoelectric technologies for power generation. In: Zhao X., Ma X., editors. Adv. Energy effic. Technol. Sol. Heating, cool. Power gener.. Cham: Springer International Publishing; 2019. p. 341-371. doi:10.1007/978-3-030-17283-1 10.

[3] Li G., Shittu S., Diallo T.M.O., Yu M., Zhao X., Ji J. A review of solar photovoltaic-thermoelectric hybrid system for electricity generation. Energy 2018;158:41-58. doi:10.1016/j.energy.2018.06.021.

[4] Li G., Diallo T.M.O., Akhlaghi Y.G., Shittu S., Zhao X., Ma X., et al. Simulation and experiment on thermal performance of a micro-channel heat pipe under different evaporator temperatures and tilt angles. Energy 2019;179:549-557. doi:10.1016/j.energy.2019.05.040.

[5] Shittu S., Li G., Zhao X., Ma X., Akhlaghi Y.G., Ayodele E. Optimized high performance thermoelectric generator with combined segmented and asymmetrical legs under pulsed heat input power. J Power Sources 2019;428:53-66. doi:10.1016/j.jpowsour.2019.04.099.

[6] Li G., Shittu S., Zhao X., Ma X., zhou K., Zhao X., et al. Preliminary experiment on a novel photovoltaic-thermoelectric system in summer. Energy 2019;188:116041. doi:10.1016/j.energy.2019.116041.

[7] Elsarrag E., Pernau H., Heuer J., Roshan N., Alhorr Y., Bartholomé K. Spectrum splitting for efficient utilization of solar radiation: a novel photovoltaic-thermoelectric power generation system. Renewables Wind Water. Sol 2015;2:16. doi:10.1186/s40807-015-0016-y.

[8] Huen P., Daoud W.A. Advances in hybrid solar photovoltaic and thermoelectric generators. Renew Sustain Energy Rev 2017;72:1295-1302. doi:10.1016/j.rser.2016.10.042.

[9] Narducci D., Bermel P., Lorenzi B., Wang N. Hybrid and fully thermoelectric solar harvesting. first ed. Switzerland: Springer International Publishing; 2018. doi:10.1109/IPDPS.2006.1639640.

[10] Shittu S., Li G., Zhao X., Ma X. Series of detail comparison and optimization of thermoelectric element geometry considering the PV effect. Renew Energy 2019;130:930-942. doi:10.1016/j.renene.2018.07.002. 
[11] Shittu S., Li G., Akhlaghi Y.G., Ma X., Zhao X., Ayodele E. Advancements in thermoelectric generators for enhanced hybrid photovoltaic system performance. Renew Sustain Energy Rev 2019;109:24-54. doi:10.1016/j.rser.2019.04.023.

[12] Shittu S., Li G., Xuan Q., Zhao X., Ma X., Cui Y. Electrical and mechanical analysis of a segmented solar thermoelectric generator under nonuniform heat flux. Energy 2020;199:117433. doi:10.1016/j.energy.2020.117433.

[13] Li G., Chen X., Jin Y. Analysis of the primary constraint conditions of an efficient photovoltaic-thermoelectric hybrid system. Energies 2017;10:1-12. doi:10.3390/en10010020.

[14] Fan L., Zhang G., Wang R., Jiao K. A comprehensive and time-efficient model for determination of thermoelectric generator length and crosssection area. Energy Convers Manag 2016;122:85-94. doi:10.1016/j.enconman.2016.05.064.

[15] Cheng F., Hong Y., Li W., Guo X., Zhang H., Fu F., et al. A thermoelectric generator for scavenging gas-heat: from module optimization to prototype test. Energy 2017;121:545-560. doi:10.1016/j.energy.2017.01.025.

[16] He H., Wu Y., Liu W., Rong M., Fang Z., Tang X. Comprehensive modeling for geometric optimization of a thermoelectric generator module. Energy Convers Manag 2019;183:645-659. doi:10.1016/j.enconman.2018.12.087.

[17] Li G., Shittu S., Ma X., Zhao X. Comparative analysis of thermoelectric elements optimum geometry between Photovoltaic-thermoelectric and solar thermoelectric. Energy 2019;171:599-610. doi:10.1016/j.energy.2019.01.057.

[18] Hashim H., Bomphrey J.J., Min G. Model for geometry optimisation of thermoelectric devices in a hybrid PV/TE system. Renew Energy 2016;87:458-463. doi:10.1016/j.renene.2015.10.029.

[19] Mahmoudinezhad S., Atouei S.A., Cotfas P.A., Cotfas D.T., Rosendahl L.A., Rezania A. Experimental and numerical study on the transient behavior of multi- junction solar cell-thermoelectric generator hybrid system. Energy Convers Manag 2019;184:448-455. doi:10.1016/j.enconman.2019.01.081.

[20] Lamba R., Kaushik S.C. Solar driven concentrated photovoltaic-thermoelectric hybrid system: numerical analysis and optimization. Energy Convers Manag 2018;170:34-49. doi:10.1016/j.enconman.2018.05.048.

[21] Kossyvakis D.N., Voutsinas G.D., Hristoforou E.V. Experimental analysis and performance evaluation of a tandem photovoltaic-thermoelectric hybrid system. Energy Convers Manag 2016;117:490-500. doi:10.1016/j.enconman.2016.03.023.

[22] Motiei P., Yaghoubi M., GoshtashbiRad E., Vadiee A. Two-dimensional unsteady state performance analysis of a hybrid photovoltaicthermoelectric generator. Renew Energy 2018;119:551-565. doi:10.1016/j.renene.2017.11.092.

[23] Fallah Kohan H.R., Lotfipour F., Eslami M. Numerical simulation of a photovoltaic thermoelectric hybrid power generation system. Sol Energy 2018;174:537-548. doi:10.1016/j.solener.2018.09.046.

[24] Zhu W., Deng Y., Wang Y., Shen S., Gulfam R. High-performance photovoltaic-thermoelectric hybrid power generation system with optimized thermal management. Energy 2016;100:91-101. doi:10.1016/j.energy.2016.01.055.

[25] Abdo A., Ookawara S., Ahmed M. Performance evaluation of a new design of concentrator photovoltaic and solar thermoelectric generator hybrid system. Energy Convers Manag 2019;195:1382-1401. doi:10.1016/j.enconman.2019.04.093.

[26] Högblom O., Andersson R. Analysis of thermoelectric generator performance by use of simulations and experiments. J Electron Mater 2014;43:2247-2254. doi:10.1007/s11664-014-3020-x.

[27] Yin E., Li Q., Xuan Y. Thermal resistance analysis and optimization of photovoltaic-thermoelectric hybrid system. Energy Convers Manag 2017;143:188-202. doi:10.1016/j.enconman.2017.04.004.

[28] Shittu S., Li G., Zhao X., Akhlaghi Y.G., Ma X., Yu M. Comparative study of a concentrated photovoltaic-thermoelectric system with and without flat plate heat pipe. Energy Convers Manag 2019;193:1-14. doi:10.1016/j.enconman.2019.04.055.

[29] Shittu S., Li G., Zhao X., Ma X., Akhlaghi Y.G., Fan Y. Comprehensive study and optimization of concentrated photovoltaic-thermoelectric considering all contact resistances. Energy Convers Manag 2020;205:112422. doi:10.1016/j.enconman.2019.112422.

[30] Evans D.L. Simplified method for predicting photovoltaic array output. Sol Energy 1981;27:555-560.

[31] Zhou J., cheng, Zhang Z., Liu H., jian, Yi Q. Temperature distribution and back sheet role of polycrystalline silicon photovoltaic modules. Appl Therm Eng 2017;111:1296-1303. doi:10.1016/j.applthermaleng.2016.10.095.

[32] Li G., Zhou K., Song Z., Zhao X., Ji J. Inconsistent phenomenon of thermoelectric load resistance for photovoltaic-thermoelectric module. Energy Convers Manag 2018;161:155-161. doi:10.1016/j.enconman.2018.01.079.

[33] Li G., Zhou K., Liu H. Simulation and experiment of a PV-MCHP-TE system and ambient parameters impacts. Int Energy Res 2020;1-10. doi:10.1002/er.5240.

[34] Shittu S., Li G., Xuan Q., Xiao X., Zhao X., Ma X. Transient and non-uniform heat flux effect on solar thermoelectric generator with phase change material. Appl Therm Eng 2020;173:115206. doi:10.1016/j.applthermaleng.2020.115206. 
Shittu S., Li G., Zhao X., Zhou J., Ma X. Experimental study and exergy analysis of photovoltaic-thermoelectric with flat plate micro-channel

heat pipe. Energy Convers Manag 2020;207:112515. doi:10.1016/j.enconman.2020.112515.

[36] He H., Liu W., Wu Y., Rong M., Zhao P., Tang X. An approximate and efficient characterization method for temperature-dependent parameters of thermoelectric modules. Energy Convers Manag 2019;180:584-597. doi:10.1016/j.enconman.2018.11.002.

[37] Met Office. MIDAS Open: UK hourly solar radiation data v201901. Cent Environ Data Anal 2019. doi:10.5285/1e040656ae0a4646acafbef6144b10f2.

[38] Met Office. MIDAS Open: UK hourly weather observation data v201901. Cent Environ Data Anal 2019. dni.10 5785/r58c1affoh0745fda4cdf487a9547185

\section{Highlights}

- Concentrated photovoltaic-thermoelectric with different leg geometries is presented.

- Optimum thermoelectric geometry in a hybrid system is investigated.

- Thermoelectric geometry optimization stabilizes hybrid system transient performance.

- Conventional symmetrical thermoelectric leg geometry is better for hybrid system.

\section{Queries and Answers}

Query: Your article is registered as a regular item and is being processed for inclusion in a regular issue of the journal. If this is NOT correct and your article belongs to a Special Issue/Collection please contact s.venkiteswaran@elsevier.com immediately prior to returning your corrections.

Answer: Yes

Query: Please confirm that given names and surnames have been identified correctly and are presented in the desired order and please carefully verify the spelling of all authors' names.

Answer: Yes

Query: Please confirm that the provided emails “Guiqiang.Li@hull.ac.uk, Xudong.Zhao@hull.ac.uk” are the correct address for official communication, else provide an alternate e-mail address to replace the existing one, because private e-mail addresses should not be used in articles as the address for communication.

Answer: Yes

Query: Have we correctly interpreted the following funding source(s) and country names you cited in your article: EU, European Union; Marie Curie, United Kingdom?

Answer: Yes 